\title{
Signal transduction by tumour necrosis factor and tumour necrosis factor related ligands and their receptors
}

\author{
Bryant G Darnay, Bharat B Aggarwal
}

Many biological functions are regulated
through interactions of extracellular molecules
with their cognate cell surface receptors. The
transduction of these signals by their receptors
at the plasma membrane to the intracellular
machinery results in such cellular activities as
gene activation, protein phosphorylation, cell
proliferation, and cell destruction. Though the
kinetics of these activities may differ, their
interactions are coordinated by selective inter-
play between the receptors intracellular do-
mains and a select set of intracellular receptor
binding proteins. One such family of extracel-
lular molecules and their cell-surface receptors
are the tumour necrosis factor (TNF) family of
related cytokines and receptors, which is the
topic of this review.

Rheumatoid arthritis, a disease of joint inflammation and destruction, is the result of inappropriate activation of resident and inflammatory cells within the synovial tissue. The consequence of an initiating and as yet unknown stimulus, the cascade of inflammatory processes are chronic and self perpetuating. The inflammation in the joints characteristic of arthritis is believed to be atrributable largely to misregulation of cytokine production, abnormal expression of receptors, or the absence of counter-regulatory pathways. Two proinflammatory cytokines, $\mathrm{TNF}$ and interleukin 1 (IL1), are believed to be the major cytokines cooperating in the pathology of this disease. ${ }^{1}$ Therapeutic approaches that inhibit the interaction of these ligands with their receptors has been a successful avenue in the treatment of rheumatoid arthritis. ${ }^{2}$

One characteristic common to both TNF and IL1 is their ability to activate the transcription factor nuclear factor-kappa B $(\mathrm{NF}-\kappa \mathrm{B})$, which is responsible for regulation of a number of genes necessary for the inflammation process. ${ }^{3}$ More recently, the elucidation of the TNF and IL1 signalling pathways has provided novel candidate molecules from which to develop therapeutic inhibitors that would block NF- $\mathrm{NB}$ activation. Furthermore, additional members of the TNF family have been discovered and are also capable of activating $\mathrm{NF}-\kappa \mathrm{B}$. To date, 21 members of the TNF receptor superfamily and 17 members of the TNF ligand superfamily have been identified. Most of these ligand/receptor pairs participate in modulating various physiological processes, including the immune response, anti-tumour activity, cellular proliferation and differentiation, and apoptosis. Many of these physiological processes are controlled through a network of these and other cytokines produced by various types of cells and their aberrant regulation may result in inflammatory diseases. In this review, we would like to focus on the recent developments in the characterisation of the TNF signalling pathway learned from multiple approaches including gene disruption in mice and on reports of recently discovered members of the TNF ligand and receptor superfamilies. It is likely that these novel cytokines also cooperate in regulating the immune system, and thus may be involved in inflammatory diseases.

\section{TNF signal transduction}

Although produced primarily by activated macrophages, small amounts of TNF are produced by several other cell types. TNF is expressed as a $26 \mathrm{kDa}$ transmembrane protein, which is processed to a soluble $17 \mathrm{kDa}$ protein released via specific proteolytic cleavage. Some of the well known activities ascribed to TNF include septic shock, cytotoxicity, inflammation, and viral replication. Clearly, $\mathrm{TNF}$ is a pleiotropic cytokine perhaps because virtually all cells express at least one of the two types of TNF receptors. The signalling pathways initiated by TNF binding to its receptor have been extensively investigated, clarifying the signalling components linking receptor activation to biological activities. ${ }^{4}$ The advent of the yeast two hybrid system for identifying proteinprotein interactions and the availability of expressed sequence tag (EST) databases have assisted in the identification of a unique and novel set of signalling machinery used by TNF and other related family members. These novel adaptor proteins seem to be promiscuous and thus are used by more than one TNF receptor family member for signal transduction. Although specific functions have been assigned to these adaptors in relation to the cellular responses activated by TNF receptor engagement, the physiological relevance of each adaptor protein in the context of ligand stimulation must await its targeted disruption in mice. Where these experiments have been done, however, some unexpected findings have emerged.

Signalling cascades initiated by various members of the TNF receptor family include those that activate transcription factors (that is, $\mathrm{NF}-\kappa \mathrm{B}$ and $\mathrm{AP} 1),{ }^{3}$ protein kinases (that is, MAPK, JNK, p38), ${ }^{5}$ and proteases. ${ }^{67}$ Over the past few years, a number of novel adaptor proteins have been identified that initiate these signalling cascades. One family, the death-
Correspondence to: Dr B Darnay. 
domain proteins, ${ }^{8}$ link death receptors to downstream proteases of the caspase family necessary for activation of apoptosis. The death domain is a protein-protein interaction motif, which is a conserved stretch of approximately 90 residues. The homophillic or heterophillic interaction between death domain containing proteins is most probably through electrostatic interactions, as revealed by the structure of the death domain of Fas, ${ }^{9}$ which consists of a series of antiparallel amphipathic $\alpha$-helices with many exposed charged residues. For example, ligand binding to the cell surface receptor causes a rearrangement of the intracellular domain to oligomerise with adaptors and in turn initiate signal transduction cascades. Consistent with this model, forced overexpression of death receptors in cultured cells causes a ligand independent apoptotic effect indistinguishable from ligand stimulation. Thus, it seems that oligomerisation caused by ligand binding to the receptor initiates the signalling cascades.

A second family of adaptor proteins identified as signalling components of the TNF receptor family is the TNF receptor associated factor (TRAFs) family, which appears to function primarily in the activation of transcription factors and protein kinases. ${ }^{10}$ The TRAF family consists of six distinct proteins, each containing a ring and zinc finger motif in their $\mathrm{N}$-terminal and C-terminal domains that appear to be responsible for self association and protein interaction (fig 1). All, except for TRAF4, were identified through yeast two-hybrid screening using a cytoplasmic domain of various members of the TNF receptor family. To date, TRAF4 has no known function. The interaction of TRAF1, TRAF2, and TRAF5 with various cytoplasmic domains of TNF receptor

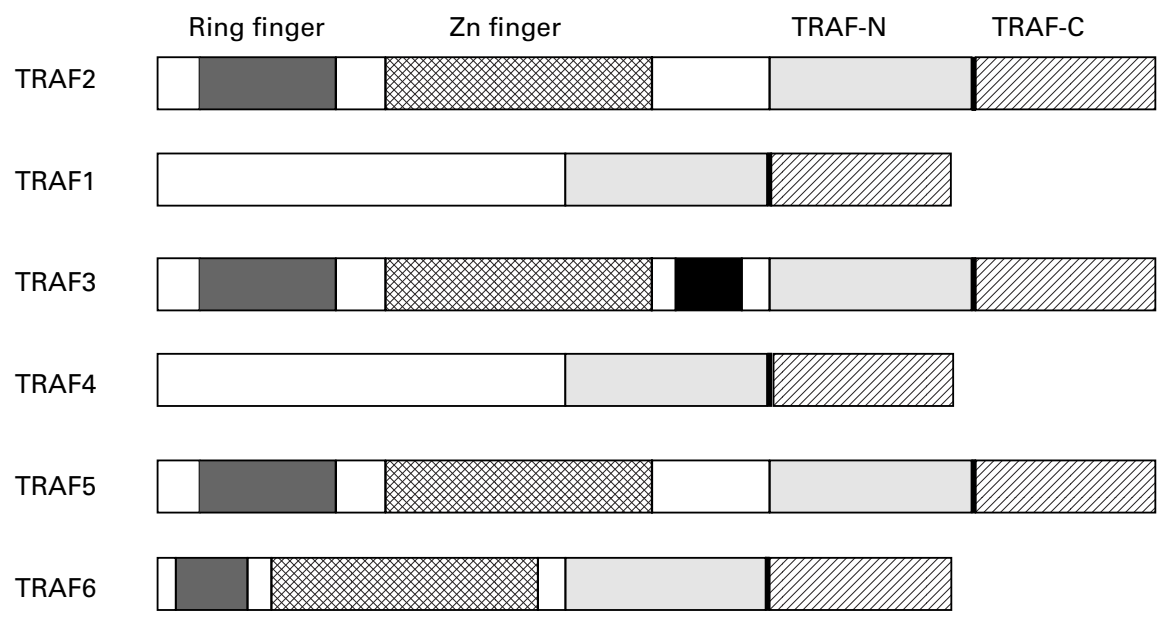

\begin{tabular}{|c|c|c|c|c|c|}
\hline$\underline{\text { Receptor }}$ & TRAF1 & TRAF2 & TRAF3 & TRAF5 & TRAFG \\
\hline TNFR2 & + & + & - & - & - \\
\hline LT $\beta$ R & + & + & + & + & $?$ \\
\hline CD40 & + & + & + & + & + \\
\hline CD30 & + & + & + & + & $?$ \\
\hline $\mathrm{CD} 27$ & $?$ & + & - & + & - \\
\hline HVEM & + & + & + & + & - \\
\hline RANK & + & + & + & + & + \\
\hline LMP-1 & + & + & + & - & - \\
\hline IL1R & - & - & - & - & + \\
\hline OX40 & - & + & + & - & $?$ \\
\hline 4-1BB & + & + & - & - & $?$ \\
\hline GITR & + & + & + & - & - \\
\hline
\end{tabular}

Figure 1 The TRAF family of proteins. Top, each of the TRAF molecules is depicted with the indicated motifs. Bottom, members of the TNF receptor family are listed with the TRAF molecules that directly interact with the receptor. LMP-1 and IL1 receptors are not members of this family, but have been shown to bind to TRAF molecules. 
family members requires a specific motif in the receptor (that is, PXQXT). Unlike these TRAF molecules, TRAF6 uses a distinct motif (that is, QXPXE), which has been identified in CD40 and RANK. ${ }^{11}{ }^{12}$ However, of the known TRAF molecules, only TRAF2, TRAF5, and TRAF6 have been demonstrated to mediate $\mathrm{NF}-\kappa \mathrm{B}$ and JNK activation.

Over the past few years, the signalling machinery linking the TNF receptor to three downstream targets (that is, apoptosis, $\mathrm{NF}-\kappa \mathrm{B}$, and JNK activation) has been elucidated (fig 2 ). To understand the complexity of the identification of the signalling components of a pathway, one must first understand how they are identified. For example, after the adaptor is identified, it is examined for its ability to either activate or inhibit downstream signalling pathways by transfection of its cDNA into cultured cells. Furthermore, a mutant version of the potential adaptor molecule is introduced into cells and examined for its ability to inhibit a specific ligand dependent end point. If the mutant version blocks this pathway, then one concludes this adaptor molecule participates in signalling by the tested ligand. Although this is not a foolproof scheme, it has become a very powerful tool in the study of the signalling events affected by TNF and other members of this family. There are potential pitfalls to arriving at general conclusions when performing these types of experiments. ${ }^{413}$ However, the physiological role of these adaptor molecules in TNF signalling and development has been recently revealed by targeted disruption of their genes in mice, most notably TRAF2, RIP, FADD, caspase 8, and FAN.

One of the first molecules to be identified and required for NF- $\mathrm{NB}$ and JNK activation by TNF was TRAF2. Initially, when it was discovered, this protein was shown to activate $\mathrm{NF}-\kappa \mathrm{B}$, and was later found to activate JNK when overexpressed in cultured cells. Furthermore, a mutant version of TRAF2 could inhibit TNF induced NF- $\mathrm{NB}$ and JNK. Thus, from the early reports it appeared that TRAF2 was essential for TNF dependent NF- $\kappa B$ activation. However, from the TRAF2 knockout mouse model, TNF could surprisingly still activate $\mathrm{NF}-\kappa \mathrm{B}$ in embryonic fibroblasts, but not JNK. ${ }^{14}{ }^{15}$ Furthermore, TRAF2 -/- mice appeared normal at birth but became progressively runted and died prematurely. Defects in B cell precursors and atrophy of the thymus were also observed. Moreover, these mice exhibited increased serum concentrations of TNF, and thymocytes and haematopoietic cells were highly sensitive to TNF induced apoptosis. These observations suggest that TRAF2 is required for TNF induced JNK activation and also important in the regulation of lymphocyte function and growth.

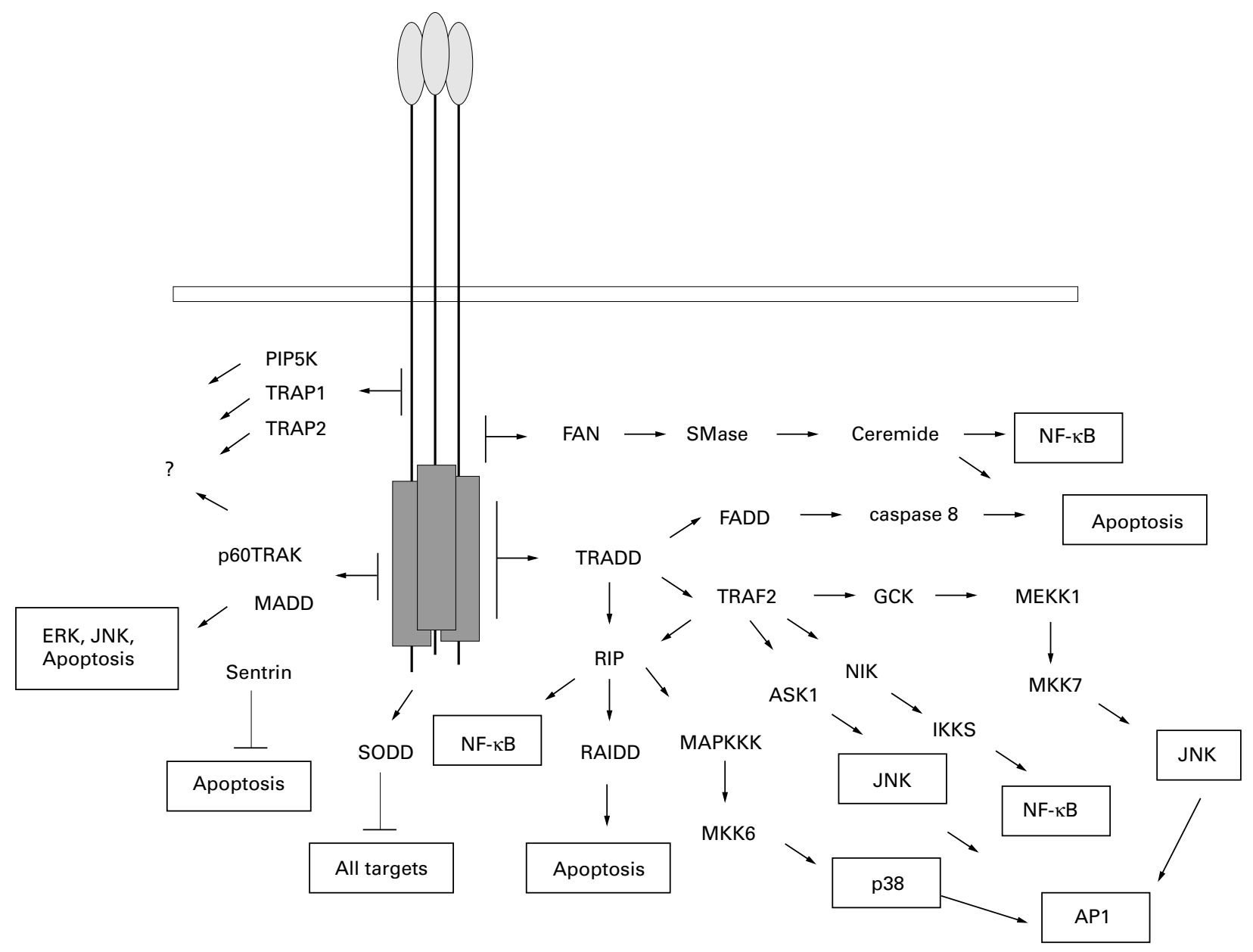

Figure 2 Schematic diagram of TNF signal transduction molecules and the biological activities activated by the adaptor proteins. 
RIP, or receptor interacting protein, which was initially identified as a Fas associated death domain kinase, seems not to play a part in Fas mediated apoptosis but rather in TNF mediated NF- $\kappa \mathrm{B}$ activation. ${ }^{16-18}$ In vitro RIP activates apoptosis, $\mathrm{NF}-\kappa \mathrm{B}$ and $\mathrm{JNK}$; however, the physiological role of RIP was determined by targeted disruption of its gene in mice. ${ }^{18} \mathrm{RIP}$ deficient mice appear normal at birth but begin to deteriorate by extensive apoptosis in both the lymphoid and adipose tissues and die at 1-3 days of age. Although TNF and Fas are able to activate apoptosis in RIP -/- cells, TNF fails to activate $\mathrm{NF}-\kappa \mathrm{B}$. Thus, it appears that RIP, but not TRAF2, is required for TNF induced $\mathrm{NF}-\kappa \mathrm{B}$ activation.

The Fas associated death domain, or FADD (Mort1), was originally identified by its ability to associate with the Fas death domain. ${ }^{19}{ }^{20}$ Subsequently, a mutant version of FADD inhibited TNF, Fas, and DR3 induced apoptosis, but not activation of NF- $\kappa \mathrm{B},{ }^{21}{ }^{22}$ suggesting that the activation of $\mathrm{NF}-\kappa \mathrm{B}$ and apoptosis are separable. The physiological role of FADD was elucidated in mice lacking FADD. ${ }^{22-24}$ The FADD-/- mice did not survive past day 11.5 of embryogenesis because of extensive abdominal haemorrhage and cardiac failure. Furthermore, FADD -/- mice are not susceptible to TNF, Fas, and DR3 induced apoptosis, but the apoptosis pathway induced by DR4 remains intact. Thus, not only is FADD required to initiate apoptosis by some death receptors, but also FADD appears to be required for embryonic development.

FADD-homologous ICE/CED-3-like protease, or FLICE (MACH1), was originally discovered in a stimulated Fas complex ${ }^{25}$ and by a yeast two-hybrid screen using FADD as the bait. ${ }^{26}$ Based on its homology to other caspases, FLICE was later designated caspase 8. Upon ligation, the $\mathrm{TNF}$ receptor recruits the death domain protein TRADD (TNF receptor associated death domain), ${ }^{27}$ which interacts with FADD and engages caspase 8 to initiate the apoptotic pathway. This signalling pathway was verified in mice lacking caspase $8 .^{28}$ Similar to the FADD -/- mice, targeted disruption of caspase 8 in mice was lethal because of impaired heart muscle development and congested accumulation of erythrocytes. Although the ability of TNF to activate NF- $\kappa \mathrm{B}$ and JNK was not impaired, caspase 8 -/- mice exhibited a defect in activation of apoptosis by TNF, Fas, and DR3. Thus, of these known death receptors, all appear to require caspase 8 as the initiating caspase leading to apoptosis.

Besides its apoptotic and inflammatory responses, TNF also generates other signalling molecules including ceramide, which is a lipid second messenger. ${ }^{4}$ Ceramide is generated from the lipid sphingosine by the activation of neutral sphingomyelinase (N-SMase). To link TNF receptor activation to sphingmyelinase activity, another protein was identified by a yeast two-hybrid screen and designated FAN, or factor associated with N-SMase activation. ${ }^{29}$ TNFR1 interacts with FAN through a small region $\mathrm{N}$-terminal to the death domain. ${ }^{29}$ To analyse the physiological role of FAN in TNF activation of N-SMase, FAN deficient mice were generated. ${ }^{30}$ FAN -/- mice are born healthy and exhibit no overt phenotypic abnormalities, but the ability of TNF to activate $\mathrm{N}$-SMase was impaired in FAN -/- mice. Signalling through TNFR1, TNF promotes skin permeability barrier repair involving sphingomyelinase. As this repair process of the cutaneous barrier leads to the proliferation of the epidermis, FAN -/- mice have a reduced ability to cause this repair process. Although the lack of FAN does not appear to inhibit other TNF signalling pathways, FAN does appear to be involved in the activation of $\mathrm{N}-\mathrm{SMase}$ by $\mathrm{TNF}$.

New members of the TNF receptor family The TNF receptor family consists of 21 known members, which are characterised by two to four homologous cysteine rich repeats in their extracelluar domain. Members of this receptor superfamily contain no significant homology within their intracellular domains, except for those that possess a death domain. Despite not having intrinsic enzymatic activity, the TNF receptor family recruits novel adaptor proteins, primarily death domain containing proteins and proteins of the TRAF family. Some members of the TNF ligand superfamily bind more than one receptor, as is the case for TRAIL, which binds five distinct receptors (that is, TRAIL R1-R4 and OPG) and LIGHT, which binds two receptors (that is, HVEM and LT $\beta R$ ). However, which receptor-ligand pairs are physiologically relevant remains to be determined. The previously described TNF receptor family members (TNFRI, TNFR2, LT $\beta R$, Fas, NGFR, CD27, CD30, CD40, OX40, and 41BB) have been reviewed elsewhere. ${ }^{31}{ }^{32}$ In this review we will introduce the recently discovered members of this receptor family (table 1). The TNF receptor family can be divided into three groups: (1) those that contain a death domain, (2) those that do not contain a death domain, and (3) those that lack a transmembrane domain, and thus are secreted, soluble forms that may in fact inhibit cytokine signalling.

DEATH RECEPTOR 3 (DR3, LARD, WSL-1, TRAMP) Death receptor 3 was identified by a search for TNF receptors using the extracellular domain, the death domain homologous regions, and an EST database. ${ }^{22}$ Others identified this receptor and named it LARD, ${ }^{33}$ WSL- $1,{ }^{34}$ or TRAMP. ${ }^{35}$ DR3 encodes a protein of 417 amino acids with a death domain contained between residues 335 and 413 . The mRNA expression pattern was restricted to spleen, thymus, colon, intestine, prostate, and PBLs. Upon $\mathrm{T}$ cell activation, a selective change in its alternative splicing results in predominantly the membrane bound form, which may have implications in lymphocyte proliferation after activation. ${ }^{33}$ The ligand for DR3 has now been demonstrated to be TWEAK. ${ }^{36}$ Signal transduction by DR3 seems to use adaptor proteins such as TRADD, TRAF2, FADD, and FLICE. $^{22}$ When overexpressed, DR3 activates $\mathrm{NF}-\kappa \mathrm{B}$, apoptosis, and JNK. ${ }^{22}$ 
TRAIL RECEPTORS (TRAIL R1- R4)

The first receptor for TRAIL was identified through a search of an EST database for TNF receptor family members and was termed death receptor 4 (DR4), ${ }^{37}$ also known as TRAIL-R $1,{ }^{38}$ after which various laboratories identified three more receptors for TRAIL, TRAIL-R2 (DR5, TRICK2, KILLER, Apo2), ${ }^{38-45}$ TRAIL-R3 (DcR1, TRID) ${ }^{38} 40$ 46-48 and TRAIL-R4 (DcR2, TRUNDD, LIT). ${ }^{49-51}$

The TRAIL receptors have been extensively reviewed. ${ }^{82-59}$ These receptors are present in a wide variety of normal tissues and in normal and tumour cell lines. Unlike TRAIL-R1 and -R2, TRAIL-R3 does not contain an intracellular domain and TRAIL-R4 contains an incomplete death domain. These data suggest that TRAIL-R3 and -R4 could serve as decoy receptors for TRAIL on the cell surface and protect the cells from TRAIL induced apoptosis. ${ }^{53}$ Consistent with this idea, overexpression of either decoy receptor in TRAIL sensitive cell lines protect them from TRAIL induced apoptosis. There are reports, however, suggesting that cells expressing R3 and R4 are still susceptible to TRAIL induced apoptosis, (Griffiths and Lynch $^{57}$ and unpublished data), though there appears to be a direct correlation of the expression of the cytoplasmic caspase inhibitor (FLIP) to the protection of TRAIL induced apoptosis. However, the results of extensive studies by various laboratories have been somewhat contradictory. Some of the adaptor proteins that may be used by the TRAIL receptors include TRADD, FADD, caspase 8, caspase 10, and FLIPs. Furthermore, there are contradictory reports on whether TRAIL or its receptors activate $\mathrm{NF}-\kappa \mathrm{B}$, perhaps because certain cell types may or may not have the adaptor proteins necessary for TRAIL to induce NF- $\mathrm{NB}$ via the TRAIL receptors. An additional decoy receptor for TRAIL, osteoprotegerin (OPG), a soluble receptor that binds RANKL (see below), binds TRAIL at nanomolar concentrations and inhibits TRAIL induced apoptosis. ${ }^{60}$ However, OPG's physiological role in TRAIL induced apoptosis is not known. Thus, more information must be obtained before any conclusions can be proposed for the signal transduction by TRAIL and its receptors.

\section{DEATH RECEPTOR 6 (DR6)}

To identify additional members of the TNF receptor family, we searched an EST database for genes with homology to both the extracellular domain and a consensus death domain. We identified a novel receptor gene and named it DR6. ${ }^{61}$ DR6 consists of 655 amino acids. Its intracellular domain contains a death domain homologous to other known death receptors, with maximum identity with TNFR1 $(27.2 \%)$ and minimum identity with TRAIL-R2 $(19.7 \%)$. Unlike other death receptors, the death domain of DR6 is located proximal to the transmembrane domain, but the significance of this difference is unclear. Curiously, following the death domain is a putative leucine zipper sequence that overlaps a proline rich domain, similar to an $\mathrm{SH} 3$ binding motif. Furthermore, two putative TRAF binding motifs are found near the transmembrane region. The C-terminus contains a region predicted to have alpha helical character. What role these domains have in signalling by DR6 remains to be determined.

The transcript for DR6 was expressed abundantly in brain, heart, placenta, pancreas, lymph node, thymus, and prostate and minimally expressed in liver and PBLs. Among cell lines examined, non-lymphoid tumour cells (HeLa S3, SW480, A549, and G361) had the highest expression of DR6; haematopoietic cell

Table 1 New members of the TNF receptor superfamily

\begin{tabular}{|c|c|c|c|}
\hline Abbreviation & Receptor name & Alternative names & Ligand \\
\hline DR3 & Death Receptor $\underline{3}$ & LARD, WSL-1, TRAMP & TWEAK \\
\hline LARD & Lymphocyte-associated Receptor of Death & DR3, WSL-1, TRAMP & TWEAK \\
\hline WSL-1 & & DR3, LARD, TRAMP & TWEAK \\
\hline TRAMP & TNF Receptor-associated Apoptosis-mediating Protein & DR3, LARD, WSL-1 & TWEAK \\
\hline DR4 & Death Receptor 4 & TRAIL-R1 & TRAIL \\
\hline DR5 & $\bar{D}$ eath $\bar{R}$ eceptor $\overline{5}$ & TRAIL-R2, TRICK2, KILLER, Apo2 & TRAIL \\
\hline DcR1 & Decoy $\underline{\text { Receptor }} \overline{1}$ & TRAIL-R3, TRID & TRAIL \\
\hline DcR2 & $\overline{\text { Decoy }} \overline{\text { Receptor }} \overline{2}$ & TRAIL-R4, TRUNDD, LIT & TRAIL \\
\hline TRAIL-R1 & $\overline{\text { TRAIL }}$ Receptor $\underline{1}$ & DR4 & TRAIL \\
\hline TRAIL-R2 & $\overline{\text { TRAIL }} \overline{\text { Receptor }} \overline{2}$ & DR5, TRICK2, KILLER, Apo2 & TRAIL \\
\hline TRAIL-R3 & TRAIL Receptor $\frac{1}{3}$ & TRID, DcR1 & TRAIL \\
\hline TRAIL-R4 & TRAIL Receptor $\underline{4}$ & TRUNDD, DcR3, LIT & TRAIL \\
\hline TRICK2 & $\overline{\text { TRAIL }} \bar{R}$ eceptor Inducer of Cell Killing & DR5, TRAIL-R2, KILLER, Apo2 & TRAIL \\
\hline KILLER & & DR5, TRAIL-R2, TRICK2, Apo2 & TRAIL \\
\hline Apo2 & Apoptosis Receptor 2 & DR5, TRAIL-R2, KILLER, TRICK2 & TRAIL \\
\hline TRID & TRAIL Receptor Without Intracellular Domain & TRAIL-R3, DcR1 & TRAIL \\
\hline TRUNDD & $\bar{T}$ TAIL Receptor With a Truncated Death Domain & TRAIL-R4, DcR2, LIT & TRAIL \\
\hline LIT & Lymphocyte Inhibitor of $\overline{\text { TRAII }}$ & TRAIL-R4, TRUNDD, DcR2 & TRAIL \\
\hline RANK & $\overline{\mathrm{R}}$ eceptor Activator of $\mathrm{NF- \overline {k } B}$ & TRANCE-R & RANKL \\
\hline TRANCE-R & $\overline{\mathrm{T} R A N C \bar{E} \text { Receptor }}$ & RANK & RANKL \\
\hline OPG & Osteoprotegerin & FDCR-1, OCIF, TR1 & TRAIL, RANKL \\
\hline FDCR-1 & 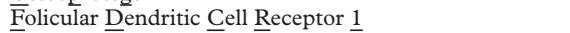 & OPG, OCIF, TR1 & TRAIL, RANKL \\
\hline OCIF & $\overline{\text { O}}$ steoclast In $n$ hibitor $\overline{\text { Factor }}$ & OPG, TR1, FDCR-1 & TRAIL, RANKL \\
\hline TR1 & TNF Receptor-related Receptor 1 & OPG, FDCR-1, OCIF & TRAIL, RANKL \\
\hline DR6 & $\bar{D}$ eath Receptor 6 & & unknown \\
\hline DcR3 & $\overline{\bar{D}}$ ecoy $\overline{\mathrm{R}}$ eceptor $\overline{3}$ & TR6 & FasL,LIGHT \\
\hline TR6 & $\overline{\mathrm{T}} \overline{\mathrm{NF}}$ receptor-related receptor 6 & DcR3 & FasL, LIGHT \\
\hline HVEM & Herpesvirus Entry Mediator & TR2, ATAR & LIGHT \\
\hline TR2 & TNF Receptor-related Receptor 2 & ATAR, HVEM & LIGHT \\
\hline ATAR & Ānother TRAF-associated Receptor & HVEM, TR2 & LIGHT \\
\hline GITR & Glucocorticoid-induced TNF-like Receptor & & GITRL \\
\hline AITR & Activation-induced TNF-like Receptor & & GITRL \\
\hline
\end{tabular}


lines (HL-60, K562, Molt4, Raji) the lowest. As with other death receptors, overexpression of DR6 induced apoptosis of HeLa cells but this was not observed in MCF-7 cells, indicating cell type specificity. As MCF-7 cells are known to be quite sensitive to TNFR1, Fas, and DR4, it may be that the mechanism of cell killing by DR6 differs from that of other death receptors. The deletion of the death domain from DR6 abolished its ability to induce apoptosis. In co-transfection and immunoprecipitation assays DR6 interacted weakly with TRADD and not at all with other death domain proteins, including FADD, RIP, and RAIDD. Thus, DR6 may activate apoptosis by associating with other novel, unknown death proteins.

Like most other death receptors, overexpression of DR6 induced NF- $\mathrm{NB}$ activation; this was abolished when the death domain was eliminated, suggesting there is a common adaptor molecule for $\mathrm{NF}-\kappa \mathrm{B}$ and apoptosis. Overexpression of DR6 also activated JNK; this response was not abolished on truncation of the death domain, indicating that JNK activation is mediated by a cytoplasmic region distinct from that activating NF- $\mathrm{\kappa B}$ and apoptosis. As TRAF molecules are capable of activating $\mathrm{JNK}$ and $\mathrm{NF}-\kappa \mathrm{B}$ and as DR6 contains two potential TRAF binding motifs, it is possible that DR6 uses TRAF molecules to activate $\mathrm{NF}-\kappa \mathrm{B}$ and $\mathrm{JNK}$.

Unlike other death receptors (that is, TNFR1, Fas, DR3, DR4, and DR5), which are expressed in most tissues and haematopoietic cells, DR6 is expressed only in cells of non-haematopoietic origin, suggesting that its physiological role may differ. In addition, the death domain of DR6 is located proximal to the transmembrane domain, rather than at the C-terminus of the receptor, and DR6 contains at least three more protein interaction motifs than the other death receptors (leucine zipper, SH3, and a C-terminal helical domain) located C-terminal to the death domain, which suggests that DR6 may in fact activate other signalling cascades. DR6 induces apoptosis in a cell type specific manner and is a potent activator of $N F-\kappa B$ and JNK. Finally, because TRADD interacts weakly with DR6, other, alternate signalling components may be used by DR6.

DECOY RECEPTOR 3 (DCR3/TR6)

A search of the EST databases for other TNF receptor related genes identified a novel member of the TNF receptor family, which was named DcR3 ${ }^{62}$ or TR6. ${ }^{63}$ DcR3 encodes a protein of 300 amino acids with a molecular mass of approximately $40 \mathrm{kDa}$. Unlike other members of this receptor family, DcR3 does not contain a transmembrane domain and thus is secreted as a soluble protein similar to OPG (see below). Its mRNA appears to be expressed in lung, brain, liver, spleen, and colon. The DcR3 transcript was detected weakly in most haematopoietic cell lines and was induced upon $\mathrm{T}$ cell activation. Interestingly, DcR3 was constitutively expressed in endothelial HUVEC cells. DcR3 binds to both LIGHT and FasL and was able to inhibit apoptosis by both of these cytokines. The expression of this soluble decoy receptor may contribute to immune system evasion by certain tumours.

RANK (RECEPTOR ACTIVATOR OF NF- $\kappa$ B)

A recently described TNF receptor family member, RANK (for receptor activator of $\mathrm{NF}-\kappa \mathrm{B}),{ }^{64}$ bears high similarity in its extracellular domain to CD40. It consists of a 616-amino acid transmembrane receptor, of which 383 amino acids reside in the intracellular domain, and does not appear to be homologous to any other family member. RANK mRNA is ubiquitiously expressed in human tissues, but cell surface RANK is expressed only on dendritic cells, the CD4+ $\mathrm{T}$ cell line $\mathrm{MP}-1$, foreskin fibroblasts, osteoclast progenitors, and activated $\mathrm{B}$ and T cells. ${ }^{64-66}$ However, its ligand RANKL (see below) appears to be restricted to activated $\mathrm{B}$ and $\mathrm{T}$ cells. RANK appears to use the TRAF family of signal transducers to activate $\mathrm{NF}-\kappa \mathrm{B}$ and JNK pathways. ${ }^{11}{ }^{67-70}$ Furthermore, a novel TRAF6 interaction motif was identified and shown to be required for activation of NF- $\mathrm{NB} .{ }^{11}$ Moreover, transgenic mice expressing a soluble form of RANK have severe osteopetrosis because of a reduction in bone resorbing osteoclasts, ${ }^{66}$ similar to OPG transgenic mice (see below). The observations that RANK interacts with TRAF6 and that TRAF6 deficient mice exhibit an osteopetrotic phenotype because of a defect in bone resorption ${ }^{71}$ suggest a direct involvement of RANK and its ligand in osteoclastogenesis. Thus, how each of these TRAF molecules regulates RANK/RANKL signal transduction pathways resulting in osteoclast differentiation and $\mathrm{B}$ and $\mathrm{T}$ cell modulation remains to be determined.

OSTEOPROTEGERIN (OPG/OCIF/TR1/FDCR-1) OPG was first identified by sequence homology as a possible novel TNF receptor family member during a rat intestine cDNA sequencing project. $^{72}$ OPG was also identified by various other laboratories and named $\mathrm{OCIF},{ }^{73}$ TR $1,{ }^{74}$ and FDCR $-1 .{ }^{25}$ OPG binds not only RANKL, ${ }^{76}$ but also TRAIL. ${ }^{60}$ Unlike the other TNF receptor family members, OPG, a 401 amino acid protein, does not contain a transmembrane domain and thus is secreted as a soluble receptor. Its mRNA is expressed in heart, placenta, lung, liver, bone marrow, spleen, lymph node, and kidney, and at lower levels in the thymus, prostate, testis, ovary, and small intestine. Initially expressed as a $55 \mathrm{kDa}$ protein, OPG is converted to a disulphide linked dimer of approximately $110 \mathrm{kDa}$ and is secreted into the medium. ${ }^{72}$ Others have confirmed that OPG is membrane associated, most likely through association with the extracellular matrix. ${ }^{75}$ In its carboxy terminus, OPG contains a homologous death domain that, when expressed as a transmembrane form, activates apoptosis. ${ }^{77}$ The main physiological feature of OPG appears to inhibit RANKL from binding to osteoclast progenitors, and thus inhibits osteoclastogenesis. ${ }^{72-74}$ Consistent with inhibition of osteoclastic cellular function, 
Table 2 New members of the TNF ligand superfamily

\begin{tabular}{|c|c|c|c|}
\hline Abbreviation & Ligand Name & Alternative Names & Receptor \\
\hline THANK & TNF Homologue that Activates NF- $\mathrm{KB}$ and JNK & TALL1, BAFF & unknown \\
\hline TALL1 & TNF and ApoL-related Leucocyte-expressed Ligand 1 & BAFF, THANK & unknown \\
\hline BAFF & $\overline{\mathrm{B}}$ cell activating factor belonging to the TNF family & TALL1, THANK & unknown \\
\hline Apo2L & Āpoptosis 2 Ligand & TRAIL & TRAIL-R1-R4, OPG \\
\hline TRAIL & TNF-related Apoptosis-Inducing Ligand & Apo2L & TRAIL-R1-R4, OPG \\
\hline TWEAK & $\overline{\mathrm{T}} N F \bar{R}$ elatedness and Weak Inducer of Apoptosis & Apo3L & DR3 \\
\hline Apo3L & Apoptosis $\underline{3}$ Ligand & TWEAK & DR3 \\
\hline VEGI & 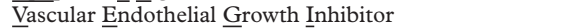 & & unknown \\
\hline RANKL & $\underline{\bar{R}}$ eceptor activator of $\underline{\mathrm{N}} \mathrm{F}-\underline{\mathrm{K}} \mathrm{B}$ Ligand & OPGL, TRANCE, ODF & RANK \\
\hline OPGL & $\overline{\text { Ossteoprotegerin Ligand }}$ & RANKL, TRANCE, ODF & RANK \\
\hline TRANCE & TNNF-related Activation-induced Cytokine & RANKL, OPGL, ODF & RANK \\
\hline ODF & Osteoclast Differentiation Factor & RANKL, OPGL, TRANCE & RANK \\
\hline LIGHT & & TL1, HVEML & HVEM, LT $\beta R$ \\
\hline TL1 & $\underline{T} N F-$ related Ligand $\underline{1}$ & HVEML, LIGHT & HVEM, LT $\beta R$ \\
\hline HVEML & $\overline{\text { He}}$ erpesvirus Entry $\underline{\text { Mediator Ligand }}$ & LIGHT, TL1 & HVEM, LT $\beta R$ \\
\hline APRIL & $\overline{\mathrm{A}}$ Proliferation-indūing Ligand & TALL2 & unknown \\
\hline TALL2 & $\underline{\overline{\mathrm{T}}} \overline{\mathrm{NF}}$ and $\underline{\text { ApoL-related Leucocyte-expressed Ligand } \underline{2}}$ & APRIL & unknown \\
\hline GITRL & 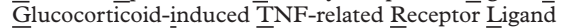 & & GITR \\
\hline
\end{tabular}

TGF- $\beta 1$ upregulated OPG mRNA while suppressing RANKL in murine bone marrow cultures. ${ }^{78}$ Moreover, OPG deficient mice exhibit an early onset of osteoporosis. ${ }^{79}$ The unique ability of OPG to increase bone mass has resulted in a potential treatment for osteoporosis, which is entering phase I clinical trials in post-menopausal women.

HERPES VIRUS ENTRY MEDIATOR (HVEM/TR2/ATAR) A novel TNF receptor family was identified by searching an EST database for a TNF related receptor protein and was termed HVEM, ${ }^{80}$ ATAR $^{81}$ and TR2. ${ }^{82}$ This receptor was also identified through a screen for receptors that would enable entry of herpes simplex virus-1 into cells. ${ }^{83}$ This receptor encodes a protein of 283 amino acids, whose mRNA expression is restricted to spleen, thymus, bone marrow, lung, small intestine, PBLs, and kidney. The ligand for this receptor was recently identified as LIGHT $^{84}$ or HVEM-L. ${ }^{85}$ The cytoplasmic domain is much shorter than in other members of this family. It uses TRAF1, TRAF2, TRAF3, and TRAF5 $5^{80-82}$ to activate NF- $\mathrm{BB}$ and JNK signalling pathways. Furthermore, a TR2-Fc fusion protein inhibited a mixed lymphocyte reaction mediated proliferation, suggesting that this receptor and its ligand may participate in $\mathrm{T}$ cell stimulation.

\section{GLUCOCORTICOID INDUCED TNFR FAMILY}

RELATED GENE (GITR/AITR)

GITR, also known as AITR, ${ }^{86}$ was identified by searching an EST database for homologues to the TNF receptor family. ${ }^{87}$ Initially, a murine GITR was identified by comparing untreated and dexamethasone treated murine $\mathrm{T}$ cell hybridoma by using the differential display technique. ${ }^{88}$ GITR encodes a protein of 241 amino acids with a molecular mass of approximately $26 \mathrm{kDa}$. The expression of GITR mRNA was highest in lymph node, PBLs, bone marrow, thymus, lung, and spleen, and relatively low in other tissues. Like most TNF receptor members, GITR was upregulated in PBMC by antigen stimulation or lymphocyte activation. The ligand for GITR was identified as GITRL. ${ }^{86}$ GITR was shown to interact with TRAF1, TRAF2, and TRAF3, and GITR induced $\mathrm{NF}-\kappa \mathrm{B}$ activation appears to require TRAF2 and NIK. Furthermore, expression of
GITR and its ligand in Jurkat T cells inhibited antigen receptor induced apoptosis, suggesting GITR may modulate T lymphocyte survival. Unlike the mouse homologue, human GITR was not induced by dexamethasone in peripheral blood $\mathrm{T}$ cells. ${ }^{86}{ }^{87}$ The observations that this receptor activates $\mathrm{NF}-\kappa \mathrm{B}$ and protects against activation induced cell death suggests that GITR and its ligand may participate in $\mathrm{T}$ lymphocyte survival in peripheral tissues and perhaps during interaction with the vascular endothelium.

\section{Novel members of the TNF family}

The TNF family consists of 17 known members. All members have a similar core sequence that is predicted to contain all 10 $\beta$-sheet forming sequences characteristic of TNF. This TNF-like core domain and the EST databases have led to the identification of new TNF related ligands. The previously described TNF family members (TNF, LT, FasL, NGF, CD27L, CD30L, CD40L, OX40L, and $41 \mathrm{BBL}$ ) have been reviewed elsewhere. ${ }^{31}{ }^{32}$ In this review we will introduce the recently identified members of this family (table 2).

TRAIL (TNF RELATED APOPTOSIS INDUCING LIGAND)

One of the first TNF related ligands that was identified was named TRAIL ${ }^{89}$ or Apo2L. ${ }^{90}$ TRAIL is a ubiquitous type II transmembrane protein of 281 amino acids. It can be cleaved from the membrane by a protease to yield a soluble protein. TRAIL specifically interacts with four membrane bound receptors known as TRAIL R1-R4 (see above) and the soluble receptor OPG, which can inhibit TRAIL induced apoptosis. ${ }^{60}$

TRAIL appears to cause apoptosis in a variety of cell types without affecting normal (nontransformed) cells. In $\mathrm{T}$ cells stimulated with PMA, ionomycin, anti-CD3, interferon $\alpha$, IL2, or IL15 expression of TRAIL is upregulated..$^{91}$ Furthermore, TRAIL is upregulated upon IFN $\alpha$ or $\gamma$ stimulation of monocytes, which then acquire the ability to kill tumour cells. ${ }^{93}$ Others have demonstrated the ability of TRAIL to induce apoptosis in human melanoma cells through caspase 8 and $3,{ }^{94}$ in melanoma cells that were resistant to FasL induced cell killing, ${ }^{95}$ and in phenotypically 
immature CD161+/CD56- NK cells. ${ }^{96}$ Most remarkably, TRAIL when administered systemically caused tumoricidal activity of the mammary adenocarcinoma cell line MDA-231 in mice without causing toxic side effects. ${ }^{97}$ TRAIL's ability to selectively kill transformed and not normal cells and its inability to activate the NF- $\mathrm{KB}$ pathway suggest that TRAIL may be a powerful treatment for cancer.

APRIL (A PROLIFERATION INDUCING LIGAND)

APRIL was discovered by screening a public database using a profile search based on an optimal alignment of all the currently known TNF ligand family members. ${ }^{98}$ An identical molecule was identified by a similar search and named TALL2.$^{99}$ The cDNA clone encoded a type II transmembrane protein of 250 amino acids, which contained 28 amino acids in the cytoplasmic domain, 21 amino acids in the transmembrane domain, and 201 amino acids in the extracellular domain. The sequence of APRIL showed highest similarity in its extracellular domain with FasL $(21 \%)$, TNFa $(20 \%)$, and LT $\beta$ (18\%). Expression of its mRNA revealed that APRIL was weakly expressed and restricted to a few tissues, most notably prostate, colon, spleen, pancreas, and PBLs. Interestingly, APRIL was expressed in various tumour cell lines including HL60, HeLa S3, K562, Molt-4, Raji, SW-480, A549, and G361. Remarkably, APRIL mRNA was increased in thyroid carcinoma and in lymphoma, but in the corresponding normal tissue the expression was either weak or absent.

APRIL's expression in tumour derived tissues, but not normal tissue suggested that APRIL may serve in tumour growth proliferation. Indeed, recombinant APRIL caused proliferation in Jurkat $\mathrm{T}$ lymphoma cells, in some B cell lymphomas (that is, Raji, mouse A20), and in some cell lines of epithelial origin such as COS, HeLa, and some melanomas. Further NIH-3T3 cells engineered to express APRIL increased tumour growth rate in nude mice as compared with NIH-3T3 cells expressing no ligand. The mechanism by which APRIL induces cellular proliferation is not known, but it does not appear to activate NF- $\mathrm{NB}$ or JNK. The APRIL receptor has not yet been identified, but it does not appear to be any of the known members of the TNF receptor family. The little information we do have about APRIL and its expression in tumour cells (compared with normal tissue) suggests that APRIL may play a part in tumorigenesis. Thus, antagonistic antibodies to APRIL or its receptor may have a potential for therapeutic intervention.

TWEAK (TNF RELATEDNESS AND WEAK INDUCER OF APOPTOSIS)

TWEAK was first identified as a clone that weakly hybridised to an erythropoietin probe whose primary sequence was similar to ligands of the TNF family. ${ }^{100}$ An identical molecule was identified through a screen of an EST database by its homology to TNF family members and was named Apo3L. ${ }^{36}$ TWEAK is a
249 amino acid type II transmembrane protein whose mRNA is expressed in essentially all tissues examined. Soluble recombinant TWEAK caused IL8 secretion in HT29, A375, WI-38, and A549 cells. $^{100}$ Additionally, TWEAK caused weak induction of apoptosis in HT29 cells when cultured with IFN $\gamma \cdot{ }^{100}$ In contrast, others have shown that TWEAK activates apoptosis strongly in MCF-7 cells, the activation being dependent on FADD and caspase activation. ${ }^{36}$ TWEAK specifically interacts with the death receptor, DR3. ${ }^{36}$ The activation of NF- $\kappa \mathrm{B}$ by TWEAK was also demonstrated to be TRAF2, TRADD, RIP, and NIK dependent. $^{36}$ TWEAK induces proliferation in a variety of normal endothelial cells and in aortic smooth muscle cells and reduces culture requirements of serum and growth factors. ${ }^{101}$ TWEAK induces a strong angiogenic response when implanted in rat corneas, suggesting a physiological role for TWEAK in vasculature formation in vivo. ${ }^{101}$

\section{VEGI (VASCULAR ENDOTHELIAL GROWTH}

INHIBITOR)

To identify an autocrine inhibitor of angiogenesis specific to endothelial cells, a cDNA library was constructed from RNA derived from various endothelial cells. A search for TNF homologues in this EST database showed a type II transmembrane protein of 174 amino acids with $20-30 \%$ homology to TNF family members. As the new protein was subsequently found to be able to inhibit endothelial cell growth, it was designated VEGI. ${ }^{102}$ Unlike other members of the TNF family, VEGI is expressed predominantly in endothelial cells. Local production of a secreted form of VEGI via gene transfer caused complete suppression of the growth of MC-38 murine colon cancers in syngeneic $\mathrm{C} 57 \mathrm{BL} / 6$ mice. Histological examination showed marked reduction of vascularisation in MC-38 tumours that expressed soluble but not membrane bound VEGI or were transfected with control vector. The conditioned media from soluble VEGI expressing cells showed marked inhibitory effect on in vitro proliferation of adult bovine aortic endothelial cells. VEGI is a novel angiogenesis inhibitor of the TNF family and functions in part by directly inhibiting endothelial cell proliferation, suggesting that VEGI may be highly valuable in angiogenesis based cancer therapy.

RANKL (RECEPTOR ACTIVATOR OF NF- $\kappa$ B LIGAND) Human RANK ligand (also known as OPGL, TRANCE, ODF) is a type II transmembrane protein with an approximate molecular mass of $45 \mathrm{kDa}$ and is expressed primarily on activated $\mathrm{T}$ and $\mathrm{B}$ cells and osteoclast progenitors..$^{64767303} \mathrm{~A}$ recent review is available. ${ }^{104}$ Like other ligands of the TNF superfamily, RANKL has been demonstrated to activate $\mathrm{NF}-\mathrm{KB}^{64}$ and JNK. ${ }^{103}$ Furthermore, stimulation of dendritic cells with RANKL up regulates the expression of the anti-apoptotic protein $\mathrm{Bcl}-$ $\mathrm{X}_{\mathrm{L}}$, suggesting a potential role for RANK/ RANKL in dendritic cell survival. ${ }^{105}$ RANKL was also demonstrated to be cleaved from the 
cell surface by the TNF converting enzyme. ${ }^{106}$ Moreover, RANKL has been demonstrated to play an essential part in osteoclast differentiation and activation. ${ }^{667673107108}$ Targeted disruption of RANKL in mice resulted in the essential requirement for RANKL to induce osteoclastogenesis. Additionally, RANKL deficient mice had poor lymphocyte development and lymph node organogenesis. ${ }^{109} \mathrm{~A}$ similar phenotype was also observed in TRAF6 deficient mice. ${ }^{71}$ Moreover, in rheumatoid arthritis (RA) patients, IL17 in synovial fluids upregulated RANKL. ${ }^{110}$ Concentrations of IL17 in synovial fluids were significantly higher in RA patients than in osteoarthritis patients. Anti-IL17 antibody significantly inhibited osteoclast formation induced by conditioned media from RA synovial tissues. These findings suggest that IL17 first acts on osteoblasts, producing a mediator that stimulates both COX-2 dependent PGE2 synthesis and RANKL gene expression, which in turn induce differentiation of osteoclast progenitors into mature osteoclasts. They also suggest that IL17 is a crucial cytokine for osteoclastic bone resorption in RA patients.

THANK (A TNF HOMOLOGUE THAT ACTIVATES APOPTOSIS, NF-кB, AND JNK)

By using an amino acid sequence motif of TNF and searching an EST database, a novel TNF homologue encoding 285 amino acids was identified and named THANK. ${ }^{111}$ The predicted extracellular domain of THANK is 15 , 16,18 , and $19 \%$ identical to LIGHT, FasL, TNF, and LTa, respectively. Northern blot analysis of its mRNA indicated expression in PBLs, spleen, thymus, lung, placenta, small intestine, and pancreas. THANK mRNA expression was highest in HL60 followed by $\mathrm{K} 562$, A549, and G361, but there was no expression in HeLa, Molt-4, Raji, and SW-480. Recombinant THANK protein activated $\mathrm{NF}-\kappa \mathrm{B}$ and $\mathrm{JNK}$ in the promyeloid cell line U937. Additionally, THANK induced activation of apoptosis in U937 cells. The receptor for THANK is at present unknown, but THANK does not bind TNFR1 or TNFR2. Identical molecules to THANK were identified and named TALL ${ }^{99}$ and BAFF. ${ }^{112}$

LIGHT

An additional member of the TNF family, named LIGHT, was identified by searching an EST database for sequence similarity to TNF family members. ${ }^{84} 113$ An identical molecule was identified by its interaction with HVEM and designated HVEM-L. ${ }^{85}$ LIGHT $\mathrm{mRNA}$ is highly expressed in splenocytes, activated PBLs, CD8+ tumour infiltrating lymphocytes, granulocytes, and monocytes, but it is not expressed in the thymus or in tumour cells. Additionally, LIGHT is upregulated in CD4+ and CD8+ T cells when exposed to PMA. LIGHT encodes a type II transmembrane protein of 240 amino acids. LIGHT binds not only to HVEM, but also to the LT $\beta$ receptor. A soluble, secreted form of LIGHT stimulates proliferation of T lymphocytes during allogeneic responses, inhib- its HT-29 cell growth, and weakly stimulates $\mathrm{NF}-\kappa \mathrm{B}$ dependent transcription. ${ }^{85}$

The MDA-MB-231 human breast carcinoma transected with LIGHT caused complete tumour suppression in mice. Histological examination showed marked neutrophil infiltration and necrosis. ${ }^{84}$ IFN $\gamma$ dramatically increases LIGHT mediated apoptosis, and LIGHT induces apoptosis of various tumour cells that express both LT $\beta$ and HVEM receptors. However, LIGHT was not cytolytic to the tumour cells that express only the LT $\beta$ R or HVEM or haematopoietic cells that express only the HVEM, such as PBLs, Jurkat cells, or CD8+ TIL cells. In contrast, treatment of the activated PBLs with LIGHT resulted in release of IFN $\gamma$. Taken together, LIGHT triggers distinct biological responses based on the expression patterns of its receptors on the target cells. Thus, LIGHT may play a part in the immune modulation and have a potential value in cancer therapy.

GITRL (GLUCOCORTICOID INDUCED TNFR FAMILY RELATED LIGAND)

The ligand for GITR was identified by a yeast based signal sequence trap method from a HUVEC cDNA library. ${ }^{87}$ This ligand was also identified in a EST database search for TNF related ligands, ${ }^{86}$ GITRL encodes a 177 amino acid type II transmembrane protein with a calculated mass of $20 \mathrm{kDa}$. Analysis of its mRNA revealed highest expression in small intestine, ovary, testis, and kidney, and lower to no expression in other tissues. Expression of membrane-bound GITRL was detected on cultured HUVEC. ${ }^{87}$ Expression of either GITRL or its receptor or both the ligand and receptor in Jurkat cells inhibited activation induced cell death. ${ }^{87}$ Consistent with the inhibition of apoptosis, GITRL activated the proapoptotic transcription factor NF- $\kappa B .{ }^{8687}$ Thus, GITRL may modulate peripheral $\mathrm{T}$ cell interaction with blood vessels in the periphery.

\section{Conclusions and future perspectives}

As new members of the TNF ligand and receptor superfamilies are being discovered, one interesting characteristic seems to be common, that most of these ligands have the ability to activate the transcription factor $\mathrm{NF}-\kappa \mathrm{B}$. As this factor is one of the primary modulators of the inflammatory process, it would not be surprising to find more than one of these cytokines involved in RA and other types of inflammatory diseases. As most of these ligands seem to be synthesised by cells of the immune system, it will be most important to understand how each of these cytokines act under physiological conditions. For instance, RANKL and its soluble receptor OPG, whose cDNAs were just described 18 months ago, are essential for osteoclastogenesis. Uncovering the physiological role for RANKL and OPG has recently led to the initiation of phase I clinical trials for the treatment of osteoporosis. With the availability of antibodies to these new ligands and their recombinant proteins, we are poised to investigate their physiological roles in the immune 
system and in various diseases such as RA. For example, a recent report demonstrated that the increased levels of IL17 in synovial fluid from RA patients caused an increase in osteoclastogenesis. ${ }^{110}$ This was most probably attributable to the increased expression of a novel member of the TNF family, RANKL, which is required for osteoclastogenesis, suggesting that IL17 present in synovial tissues and fluids from RA patients may be involved in the joint destruction associated with this disease. Thus, with the identification of the signalling pathways and the physiological roles associated with these new ligands, it may be possible to develop new therapeutic approaches to combat various inflammatory diseases and cancer.

Funding: this research was supported by the Clayton Foundation for Research.

1 Arend WP, Dayer JM. Inhibition of the production and effects of interleukin-1 and tumor necrosis factor (alpha) in rheumatoid arthritis. Arthritis Rheum 1995;38:151-60.

2 Moreland LW, Baumgartner SW, Schiff $\mathrm{MH}$, et al. Treatment of rheumatoid arthritis with a recombinant human tumor necrosis factor receptor (p75)-Fc fusion protein. N Engl J Med 1997;337:141-7.

3 May MJ, Gosh S. Signal transduction through NF-kB Immunol Today 1998;19:80-8.

4 Wallach D, Varfolomeev EE, Malinin NL, Goltsev YV, Kovalenko AV, Boldin MP. Tumor necrosis factor receptor and Fas signaling mechanisms. Annu Rev Immunol 1999; 17:331-67.

5 Schaeffer HJ, Weber MJ. Mitogen-activated protien kinases: specific messages from ubiquitous messengers. Mol Cell specific messages from
Biol 1999;19:2435-44.

6 Salvesen GS, Dixit VM. Caspases: intracellular signaling by proteolysis. Cell 1997;91:443-6.

7 Thornberry NA, Lazebnik Y. Caspases: enemies within. Science 1998;281:1312-16

8 Singh A, Ni J, Aggarwal BB. Death domain receptors and their role in cell demise. J Interferon Cytok Res $1998 ; 18: 439-50$

9 Huang B, Eberstadt M, Olejniczak ET, Meadows RP, Fesik SW. NMR structure and mutagenesis of the Fas (APO-1/ CD95) death domain. Nature 1996;384:638-41

10 Arch RH, Gedrich RW, Thompson CB. Tumor necrosis factor receptor-associated factors (TRAFs)-a family of adaptor proteins that regulates life and death. Genes Dev 1998;12:2821-30

11 Darnay BG, Ni J, Moore PA, Aggarwal BB. Activation of NF-kB by RANK requires TRAF6, and NF-kB-inducing kinase (NIK): identification of a novel TRAF6 interaction kinase (NIK): identification of a novel

12 Pullen SS, Dang TTA, Crute JJ, Kehry MR. CD40 signaling through tumor necrosis factor receptor-associated factors (TRAFs): binding site specificity and activation of (TRAFs): binding site specificity and activation of
downstream pathways by distinct TRAFs. J Biol Chem downstream pathway

13 Karin M, Delhase M. JNK or IKK, AP-1 or NF-kB, which are the targets for MEK kinase 1 action? Proc Natl Acad Sci 1998;95:9067-9.

14 Lee S Y, Reichlin A, Santana A, Sokol KA, Nussenzweig MC, Choi Y. TRAF2 is essential for JNK but not NF-kB activation and regulates lymphocyte proliferation and survival. Immunity 1997;7:703-13.

15 Yeh W-C, Shahinian A, Speiser D, et al. Early lethality, fucntional NF-kB activation, and increased sensitivity to TNF-induced cell death in TRAF2-deficient mice. Immunity $1997 ; 7: 715-25$

16 Ting AT, Pimentel-Muiños FX, Seed B. RIP mediates tumor necrosis factor receptor 1 activation of NF-B but not Fas/APO-1-initiated apoptosis. EMBO J 1996;15:618996.

17 Stanger BZ, Leder P, Lee T-H, Kim E, Seed B. RIP: A novel protein containing a death domain that interacts with Fas APO1 (CD95) in yeast and causes cell death. Cell 1995;81:513-23.

18 Kelliher MA, Grimm S, Ishida Y, Kuo F, Stanger BZ, Leder P. The death domain kinase RIP mediates the TNFinduced NF-kB signal. Immunity 1998;8:297-303.

19 Boldin MP, Varfolomeev EE, Pancer Z, Mett IL, Camoni $\mathrm{JH}$, Wallach D. A novel protein that interacts with the death
domain of Fas/APO1 contains a sequence motif related to the death domain. J Biol Chem 1995;270:7795-8.

20 Chinnaiyan AM, O'Rourke K, Tewari M, Dixit VM. FADD, a novel death domain-containing protein, interacts with the death domain of Fas and initiates apoptosis. Cell 1995;81: 505-12.

21 Chinnaiyan AM, Tepper CG, Seldin MF, et al. FADD MORT1 is a common mediator of CD95 (Fas/APO-1) and tumor necrosis factor receptor-induced apoptosis. J Biol tumor necrosis factor recep

22 Chinnaiyan AM, O'Rourke K, Yu G-L, et al. Signal transduction by DR3, a death domain-containing receptor related to TNFR-1 and CD95. Science 1996;274: 990-2.
23 Yeh W-C, de la Pompa JL, McCurrach ME, et al. FADD: essential for embryo development and signaling from some, but not all, inducers of apoptosis. Science 1998;279: 1954-8.

24 Zhang J, Cado D, Chen A, Kabra NH, Winoto A. Fas-mediated apoptosis and activation-induced T-cell proliferation are defective in mice lacking FADD/Mort1. Nature 1998;392:296-300

25 Muzio M, Chinnaiyan AM, Kischkel FC, et al. FLICE, a novel FADD-homologous ICE/CED-3-like protease, is recruited to the CD95 (Fas/APO-1) death-inducing signaling complex. Cell 1996;85:817-27.

26 Boldin MP, Goncharov TM, Goltsev Y V, Wallach D. Involvement of $\mathrm{MACH}$, a novel MORT1/FADDinteracting protease, in Fas/APO-1- and TNF receptorinduced cell death. Cell 1996;85:803-15.

$27 \mathrm{Hsu} \mathrm{H}$, Xiong J, Goeddel DV. The TNF receptor 1 -associated protein TRADD signals cell death and NF-kB activation. Cell 1995;81:495-504.

28 Varfolomeev EE, Schuchmann M, Luria V, et al. Targeted disruption of the mouse caspase 8 gene ablates cell death induction by the TNF receptors, Fas/Apo1, and DR3 and is lethal prenatally. Immunity 1998;9:267-76.

29 Adam-Klages S, Adam D, Weigmann K, et al. FAN, a novel WD-repeat protein, couples the p55 TNF-receptor to neutral sphingomyelinase. Cell 1996;86:937-47.

30 Kreder D, Krut O, Adam-Klages S, et al. Impaired neutral sphingomyelinase activation and cutaneous barrier repair in FAN-deficient mice. EMBO J 1999;18:2472-9.

31 Wallach D, Bigda J, Engelmann $H$. The TNF family and related molecules. In: Theze J, ed. The cytokine network and immune functions. London: Oxford University Press. (in press).

32 Aggarwal BB, Natarajan K. Tumor necrosis factors: developments during the last decade. Eur Cytokine Netw 1996;7:93-124.

33 Screaton GR, Xu X-N, Olsen AL, et al. LARD: A new lymphoid-specific death domain containing receptor regulated by alternative pre-mRNA splicing. Proc Natl Acad Sci USA 1997;94:4615-19.

34 Kitson J, Raven T, Jiang Y-P, et al. A death-domaincontaining receptor that mediates apoptosis. Nature 1996; $384: 372-5$.

35 Bodmer J-L, Burns K, Schneider P, et al. TRAMP, a novel apoptosis-mediating receptor with sequence homology to tumor necrosis factor receptor 1 and Fas (Apo-1/CD95). Immunity $1997 ; 6: 79-88$

36 Marsters SA, Sheridan JP, Pitti RM, Brush J, Goddard A, Ashkenazi A. Identification of a ligand for the deathdomain-containing receptor Apo3. Curr Biol 1998;8: 525-8.

37 Pan G, O'Rourke K, Chinnaiyan AM, et al. The receptor of the cytotoxic ligand TRAIL. Science 1997;276:111-13.

38 Schneider P, Bodmer JL, Thome M, Hofmann K, Holler N, Tschopp J. Characterization of two receptors for TRAIL. FEBS Lett 1997:416:329-34.

39 Pitti RM, Marsters SA, Ruppert S, Donahue CJ, Moore A, Ashkenazi A Induction of apoptosis by Apo-2 ligand, a new member of the tumor necrosis factor cytokine family. J Biol Chem 1996;271:12687-90.

40 Sheridan JP, Marsters SA, Pitti RM, et al. Control of TRAIL-induced apoptosis by a family of signaling and decoy receptors. Science 1997;277:818-21.

41 Schneider P, Thome M, Burns K, et al. TRAIL receptors (DR4) and 2 (DR5) signal FADD-dependent apoptosis and activate NF-kB. Immunity 1997;7:831-6.

42 Macfarlane M, Abmad M, Srinivasula SM, FernandesAlnemri T, Cohen GM, Alnemri ES. Identification and molecular cloning of two novel receptors for the cytotoxic ligand TRAIL. J Biol Chem 1997;272:25417-20.

43 Chaudhary PM, Eby M, Jasmin A, Bookwalter A, Murray J, Hood L. Death receptor 5, a new member of the TNFR family, and DR4 induce FADD-dependent apoptosis and activate NF-kB pathway. Immunity 1997;7:821-30.

44 Screaton GR, Mongkolsapaya J, Xu X-N, Cowper AE, Mcmichael AJ, Bell JI. TRICK2, a new alternatively spliced receptor that transduces the cytotoxic signal from TRAIL. Curr Biol 1997;7:693-6.

$45 \mathrm{Wu}$ GS, Burns TF, McDonald ER, et al. KILLER/DR5 is a DNA damage-inducible p53-regulated death receptor gene. Nat Genet 1997;17:141-3.

46 Degli-Esposti MA, Smolak PJ, Walczak H, et al. Cloning and characterization of TRAIL-R3, a novel member of the emerging TRAIL receptor family. J Exp Med 1997;186: $165-70$

47 Pan G, Ni J, Wei Y-F, Yu G-L, Gentz R, Dixit VM. An antagonist decoy receptor and a death domain-containing receptor for TRAIL. Science 1997;277:815-17.

48 Mongkolsapaya J, Cowper AE, Xu X-N, et al. Lymphocyte inhibitor of TRAIL (TNF-related apoptosis-inducing igand): a new receptor protecting lymphocytes from the death ligand TRAIL. J Immunol 1998;160:3-6.

49 Degli-Esposti MA, Dougall WC, Smolak PJ, Waugh JY, Smith CA, Goodwin RG. The novel receptor TRAIL-R4 induces NF-kB and protects against TRAIL-mediated apoptosis, yet retains an incomplete death domain. Immunity 1997; 7:813-20

50 Marsters SA, Sheridan JP, Pitti RM, et al. A novel receptor for Apo2L/TRAIL contains a truncated death domain. for Apo2L Biol 1997;7:1003-6.

51 Pan G, Ni J, Yu GL, Wei Y-F, Dixit VM. TRUNDD, a new member of the TRAIL receptor family that antagonizes TRAIL signalling. FEBS Lett 1998;424:41-5. 

52 French LE, Tschopp J. The TRAIL to selective tumor

53 Ashkenazi A, Dixit VM. Death receptors: Signaling and modulation. Science 1998;281:1305-8.

54 Degli-Esposti $M$. To die or not to die-the quest of the TRAIL receptors. J Leuk Biol 1999;65:535-42.

55 Darnay BG, Aggarwal BB. Early events in TNF signaling: A story of associations and dissociations. J Leuk Biol 1997;61:559-66.

56 Muzio M. Signaling by proteolysis: death receptors induce apoptosis. Int J Clin Lab Res 1998;28:141-7.

57 Griffith TS, Lynch DH. TRAIL: A molecule with multiple receptors and control mechanisms. Curr Opin Immunol receptors and co

58 Schulze-Osthoff K, Ferrari D, Los M, Wesselborg S, Peter $\mathrm{ME}$. Apoptosis signaling by death receptors. Eur J Biochem 1998;254:439-59.

59 Goldstein P. Cell death: TRAIL and its receptors. Curr Biol 1997;7:R750-3.

60 Emery JG, McDonnell P, Brigham Burke M, et al. Osteoprotegerin is a receptor for the cytotoxic ligand TRAIL J Biol Chem 1998;273:14363-7.

61 Pan G, Bauer JH, Haridas V, et al. Identification and functional characterization of DR6, a novel death domaincontaining TNF receptor FEBS Lett 1998;434:351-6.

62 Pitti RM, Marsters SA, Lawrence DA, et al. Geneomic amplification of a decoy receptor for Fas ligand in lung and colon cancer. Nature 1998;396:699-703.

63 Yu K-Y, Kwon B, Ni J, Zhai Y, Ebners, Kwon BS. A newly identified member of the tumor necrosis factor receptor superfamily (TR6) suppresses LIGHT-mediated apoptosis. J Biol Chem 1999;274:13733-6.

64 Anderson DM, Maraskovsky E, Billingsley WL, et al. A homologue of the TNF receptor and its ligand enhance T-cell growth and dendritic-cell function. Nature 1997: 390:175-9.

65 Josien R, Wong BR, Li H-L, Steinman RM, Choi, Y TRANCE, a TNF family member, is differentially expressed on $\mathrm{T}$ cell subsets and induces cytokine production in dendritic cells. J Immunl 1999;162:2562-8.

66 Hsu H, Lacey DL, Dunstan CR, et al. Tumor necrosis factor receptor family member RANK mediates osteoclast tor receptor family member RANK mediates osteoclast
differentiation and activation induced by osteoprotegerin differentiation and activation induced by osteop
ligand Proc Natl Acad Sci USA 1999;96:3540-5.

67 Darnay BG, Haridas V, Ni J, Moore PA, Aggarwal BB. Characterization of the intracellular domain of receptor activator of NF-kB (RANK): interaction with tumo necrosis factor receptor-associated factors and activation of $\mathrm{NF}-\mathrm{kB}$ and c-jun N-terminal kinase. J Biol Chem 1998;273:20551-5.

68 Wong BR, Josien R, Lee SY, Vologodskaia M, Steinman RM, Choi Y. The TRAF family of signal transducers mediates NF-kB activation by the TRANCE receptor. J Biol ates NF-kB activation by

$69 \mathrm{Kim} \mathrm{H-H}$, Lee DE, Shin JN, et al. Receptor activator of NF-kB recruits multiple TRAF family adaptors and activates c-Jun N-terminal kinase. FEBS Lett 1999;443: 297-302.

70 Galibert L, Tometsko ME, Anderson DM, Cosman D, Dougall WC. The involvement of multiple tumor necrosis factor receptor (TNFR)-associated factors in the signaling mechanisms of receptor activator of NF-kB, a member of the TNFR superfamily. J Biol Chem 1998;273:34120-7.

71 Lomaga MA, Yeh W-C, Sarosi I, et al. TRAF6 deficiency results in osteopetrosis and defective interleukin-1, CD40, and LPS signaling. Genes Dev 1999;13:1015-24.

72 Simonet WS, Lacey DL, Dunstan CR, et al. Osteoprotegerin: a novel secreted protein involved in the regulation of bone density. Cell 1997;89:309-19.

73 Yasuda H, Shima N, Nakagawa N, et al. Osteoclast differentiation factor is a ligand for osteoprotegerin osteoclastogenesis-inhibitory factor and is identical to TRANCE/RANKL. Proc Natl Acad Sci USA 1998;95 3597-602

74 Kwon BS, Wang S, Udagawa N, et al. TR1, a new member of the tumor necrosis factor receptor superfamily, induces fibroblast proliferation and inhibits osteoclastogenesis and bone resorption. FASEB J 1998;12:845-54

75 Yun TJ, Chaudhary PM, Shu GL, et al. OPG/FDCR-1, a TNF receptor family member, is expressed in lymphoid cells and is up-regulated by ligating CD40. J Immunol 1998;161:6113-21.

76 Lacey DL, Timms E, Tan H-L, et al. Osteoprotegerin ligand is a cytokine that regulates osteoclast differentiation and is a cytokine that regulates osteocion. Cell 1998;93:165-76.
activation.

77 Yamaguchi K, Kinosaki M, Goto $M$, et al. Characterization of structural domains of human osteoclastogenesis inhibitory factor. J Biol Chem 1998;273:5117-23.

78 Takai H, Kanematsu M, Yano K, et al. Transforming growth factor -B stimulates the production of osteoprotegerin osteoclastognesis inhibitory factor by bone marrow stroma cells. J Biol Chem 1998;273:27091-6.

79 Bucay N, Sarosi I, Dunstan CR, et al. Osteoprotegerindeficient mice develop early onset osteoporosis and arterial calcification. Gene Dev 1998;12:1260-8.

80 Marsters SA, Ayers TM, Skubatch M, Gray CL, Rothe M, Ashkenazi A. Herpesvirus entry mediator, a member of the tumor necrosis factor receptor (TNFR) family, interacts with members of the TNFR-associated factor family and activates the transcription factors NF-kB and AP-1. J Biol Chem 1997;272:14029-32.

81 Hsu H, Solovyev I, Colombero A, Elliott R, Kelley M, Boyle WJ. ATAR, a novel tumor necrosis factor receptor family member, signals through TRAF2 and TRAF5. J Biol Chem 1997;272:13471-4.

82 Kwon BS, Tan KB, Ni J, et al. A newly identified member of the tumor necrosis factor receptor superfamily with a wide tissue distribution and involvement in lymphocyte activation. J Biol Chem 1997;272:14272-6.

83 Montgomery RI, Warner MS, Lum BJ, Spear PG. Herpes simplex virus-1 entry into cells mediated by a novel mem36.

84 Zhai Y, Guo R, Hsu TL, et al. LIIGHT, a novel ligand for lymphotoxin receptor and TR2/HVEM induces apoptosis and suppresses in vivo tumor formation via gene transfer. J Clin Invest 1998;102:1142-51.

85 Harrop JA, McDonnell PC, Brigham-Burke M, et al. Herpesvirus entry mediator ligand (HVEM-L), a novel ligand for HVEM/TR2, stimulates proliferation of T cells and inhibits HT29 cell growth. J Biol Chem 1998;273:2754856.

86 Kwon B, Yu K-Y, Ni J, et al. Identification of a novel activation-inducible protein of the tumor necrosis factor receptor superfamily and its ligand. J. Biol Chem 1999;274:6056-61.

87 Gurney AL, Marsters SA, Huang A, et al. Identification of a new member of the tumor necrosis factor family and its receptor, a human ortholog of mouse GITR. Curr Biol 1999;9:215-18.

88 Nocentini G, Giunchi L, Ronchetti S, et al. A new member of the tumor necrosis factor/nerve growth factor receptor family inhibits T cell receptor-induced apoptosis. Proc Natl Acad Sci USA 1997;94:6216-21.

89 Wiley SR, Schooley K, Smolak PJ, et al. Identification and characterization of a new member of the TNF family that induces apoptosis. Immunity 1995;3:673-82.

90 Pitti RM, Marsters SA, Ruppert S, Donahue CJ, Moore A, Ashkenazi A. Induction of apoptosis by Apo-2 ligand, a new member of the tumor necrosis

91 Jeremias I, Herr I, Boehler T, Debatin K-M. TRAIL/Apo-2ligand-induced apoptosis in human T cells. Eur J Immunol 1998;28:143-52.

92 Kayagaki N, Yamaguchi N, Nakayama M, Eto H, Okumura $\mathrm{K}$, Yagita $\mathrm{H}$. Type I interferons (IFNs) regulate tumor necrosis factor-related apoptosis-inducing ligand (TRAIL) expression on human T cells: A novel mechanism for the antitumor effects of type I IFNs. J Exp Med 1999;189: 1451-60.

93 Griffith TS, Wiley SR, Kubin MZ, Sedger LM, Maliszewski CR, Fanger NA. Monocyte-mediated tumoricidal activity via the tumor necrosis factor-related cytokine, TRAIL. Exp Med 1999;189:1343-53.

94 Griffith TS, Chin WA, Jackson GC, Lynch DH, Kubin MZ. Intracellular regulation of TRAIL-induced apoptosis in human melanoma cells. J Immunol 1998;161:2833-40.

95 Thomas WD, Hersey P. TNF-related apoptosis-inducing ligand (TRAIL) induces apoptosis in Fas ligand-resistant melanoma cells and mediates CD4 T cell killing of target cells. J Immunol 1998;161:2195-200.

96 Zamai L. Ahmad M, Bennett IM, Azzoni L, Alnemri ES, Perussia B. Natural killer (NK) cell-mediated cytotoxicity: differential use of TRAIL and Fas ligand by immature and mature primary human NK cells. J Exp Med 1998;188: 2375-80

97 Walczak H, Miller RE, Ariail K, et al. Tumoricidal activity of tumor necrosis factor-related apoptosis-inducing ligand in vivo. Nat Med 1999;5:157-63.

98 Hahne M, Kataoka T, Schroter M, et al. APRIL, a new ligand of the tumor necrosis factor family, stimulates tumor cell growth. J Exp Med 1998;188:1185-90.

99 Shu H-B, Hu W-H, Johnson H. TALL-1 is a novel member of the TNF family that is down-regulated by mitogens. J Leuk Biol 1999;65:680-3.

100 Chicheportiche Y, Bourdon PR, Xu H, et al. TWEAK, an new secreted ligand in the tumor necrosis factor family that weakly induces apoptosis. J Biol Chem 1997;272:3240110.

101 Lynch CN, Wang YC, Lund JK, Chen Y-W, Leal JA, Wiley, SR. TWEAK induces angiogenesis and proliferation of endothelial cells. J Biol Chem 1999;274;8455-9.

102 Zhai, Y, Ni J, Jiang G-W, et al. VEGI, a novel cytokine of the tumor necrosis factor family, is an angiogenesis inhibitor that suppresses the growth of colon carcinomas in vivo. FASEB J 1999;13:181-9.

103 Wong BR, Rho J, Arron J, et al. TRANCE is a novel ligand of the tumor necrosis factor receptor family that activates c-Jun N-terminal kinase in T cells. J Biol Chem 1997;272: 25190-4.

104 Green EA, Flavell RA. TRANCE-RANK, a new signal pathway involved in lymphoctye development and $\mathrm{T}$ cell activation. J Exp Med 1999;189:1017-20.

05 Wong BR, Josien R, Lee SW, Sauter B, Li H-L, Steinman RM, Choi Y. TRANCE (Tumor necrosis factor [TNF]related activation-induced cytokine), a new TNF family member predominantly expressed in T cells, is a dendritic cell-specific survival factor. J Exp Med 1997;186:207580.

106 Lum L, Wong BR, Josien R, et al. Evidence for a role of a tumor necrosis factor-(TNFa)-converting enzyme-like protease in shedding of TRANCE, a TNF family member involved in osteoclastogenesis and dendritic cell survival. J Biol Chem 1999;274:13613-18.

107 Fuller K, Wong BR, Fox S, Choi Y, Chambers TJ. TRANCE is necessary and sufficient for osteoblast- 
mediated activation of bone resporbtion in osteoclast. J Exp Med 1998;188:997-1001.

108 Burgess TL, Qian Y-X, Kaufman S, et al. The ligand for osteoprotegerin (OPGL) directly activates mature osteo-

109 Kong Y-Y, Yoshida H, Saros I, et al. OPGL is a key regulator of osteoclastogenesis, lymphocyte development and lymph-node organogenesis. Nature 1999;397:315-23.

110 Kotake S, Udagawa N, Takahashi N, et al. IL-17 in synovial fluids from patients with rheumatoid arthritis is a
potent stimulator of osteoclastogenesis. J Clin Invest 1999;
111 Mukhopadhyay A, Ni J, Zhai Y, Yu G-L, Aggarwal BB. Identification and characterization of a novel cytokine, THANK, a TNF homologue that activates apoptosis, nuclear factor-kB, and c-Jun

112 Schneider P, MacKay F, Steiner V, et al. BAFF, a novel ligand of the tumor necrosis factor family, stimulates B cell growth. J Exp Med 1999;189:1747-56.

113 Mauri DN, Ebner R, Montgomery RI, et al. LIGHT, a new member of the TNF superfamily, and lymphoxin a are ligands for herpesvirus entry mediator. Immunity 1998;8:21- 